\title{
COMPARISON OF PEROXIDASE RESPONSE TO MENTAL ARITHMETIC STRESS IN SALIVA OF SMOKERS AND NON-SMOKERS
}

\author{
Nobuhiro GOI ${ }^{1}$, Yuuko HIRAI ${ }^{1}$, Hitoshi HARADA ${ }^{1}$, Akira IKARI ${ }^{1}$, Takahiko ONO ${ }^{1}$, Naohide KINAE $^{2}$, \\ Mitsuo HIRAMATSU ${ }^{3}$, Kimitsugu NAKAMURA ${ }^{4}$ and Kuniaki TAKAGI ${ }^{1}$ \\ ${ }^{1}$ Department of Environmental Biochemistry and Toxicology, \\ University of Shizuoka School of Pharmaceutical Science, \\ 52-1 Yada, Suruga-ku, Shizuoka 422-8526, Japan \\ ${ }^{2}$ Department of Food and Nutritional Sciences, \\ University of Shizuoka Graduate School of Nutritional and Environmental Sciences, \\ 52-1 Yada, Suruga-ku, Shizuoka 422-8526, Japan \\ ${ }^{3}$ Hamamatsu Photonics K.K. Central Research Laboratory, \\ 5000 Hirakuchi, Hamamatsu 434-8601, Japan \\ ${ }^{4}$ Hamamatsu Photonics K.K. Electron Tube Division, \\ 314-5 Shimokamizou, Iwata 438-0193, Japan
}

(Received January 5, 2007; Accepted January 23, 2007)

\begin{abstract}
Saliva is the first body fluid to encounter exogenous materials or gases such as cigarette smoke (CS). The aim of this study was to examine whether smoking affects oral peroxidase (OPO) reactivity to mental stress. The subjects were 39 non-smokers and 10 smokers. In the experiment, the Kraepelin psychodiagnostic test as a psychological stressor and saliva was sampled $30 \mathrm{~min}$ before, just before, immediately after, and $30 \mathrm{~min}$ after the beginning of the test. OPO reactivity to the test between smokers and non-smokers was measured in addition to uric acid concentration, flow rate, $\operatorname{IgA}$, thiocyanate $\left(\mathrm{SCN}^{-}\right)$ concentration, amylase activity as a salivary stress marker, and ultra-weak chemiluminescence (UCL) level, which is indicative of salivary antioxidative and antibacterial abilities. Moreover, we studied the effect of smoking on the response of salivary peroxidase (SPO) and myeloperoxidase (MPO) activity to mental stress, respectively. The results showed that the IgA concentration, amylase activity, $\mathrm{SCN}^{-}$concentration, and UCL level are higher in the non-smoking group than smoking group and the IgA concentration and UCL level increased in the non-smokers significantly just after the Kraepelin test. The levels of $\mathrm{SCN}^{-}$were higher in smokers than in non-smokers and $\mathrm{OPO}$ activity was greater in the non-smoking group in all sessions. Furthermore, only the non-smokers had significantly increased MPO activity just after the test. MPO may play a crucial role in the response to acute psychological stress besides inflammation, and CS suppresses this response significantly.
\end{abstract}

KEY WORDS: Cigarette smoke, Oral peroxidase, Psychological stress, Salivary peroxidase, Myeloperoxidase

\section{INTRODUCTION}

Saliva is the first biological medium confronted by external materials such as food, drink, or inhaled volatile factors. An extensive amount of research has been devoted to the immunological defense mecha- nisms of saliva, primarily based on secretory $\operatorname{Ig} \mathrm{A}$ $(\operatorname{sIgA})$ and protein defense based on lactoferin, lysozyme, agglutin, mucin etc. (Nogueira et al., 2005; Amerongen et al., 2004; Tenovuo, 2002). Recently, the importance of another salivary defense system has become obvious; the antioxidative defense which

Correspondence: Kuniaki TAKAGI (E-mail: takagku@ys7.u-shizuoka-ken.ac.jp) 
involves various molecules and enzymes (Nagler, 2003). The most important antioxidant is uric acid, which contributes approximately $70 \%$ of the total salivary antioxidative capacity (Nagler et al., 2002), with the role of ascorbic acid being secondary (Nagao and Terao, 1990). In the enzymatic salivary antioxidative system, peroxidase is by far the most important enzyme. Other salivary enzymes, such as superoxide dismutase (SOD), catalase, glutathione peroxidase, and glutathione reductase, have secondary or marginal antioxidative significance (Kranendonk et al., 1997).

The oral peroxidase (OPO) found in the cavity is a very important salivary antioxidant. This OPO is composed of two enzymes, salivary peroxidase (SPO) and myeloperoxidase (MPO). SPO is secreted from the major salivary glands, mainly the parotid gland (Nagler et al., 2002), while MPO is produced by leukocytes in inflammatory regions of the oral cavity (Pruitt et al., 1990). SPO contributes $60-80 \%$ of peroxidase activity and MPO contributes the remaining 20-40\% (Nagler et al., 2002; Pruitt et al., 1990).

Many studies indicate the important role of cigarette smoking in reducing the body's antioxidant content and emphasize the protective effect of antioxidant nutrients in preventing tissue damage (Stone et al., 1995; Zappacosta et al., 1999; Reznick et al., 2003; Zappacosta et al., 2002). A fairly recent study demonstrated a sharp drop in OPO activity after smoking a single cigarette in both non-smokers and smokers (Reznick et al., 2003) and suggested that reactive oxygen species (ROS), such as the hydroxyl radical, might cause oxidative DNA damage to the surrounding tissues (Pryor, 1997). In this respect, the saliva antioxidative system also contributes to anticarcinogenic capability.

In previous studies we showed that acute stress such as mental arithmetic increased OPO activity and changed several salivary biochemical parameters (Goi et al., 2007). A possible anticarcinogenic role of OPO against the most prevalent and lethal cancer of the oral cavity has been mentioned (Nagler et al., 2002; Zappacosta et al., 1999; Reznick et al., 2003), but whether the response of OPO activity to mental stress changes due to habits such as smoking has scarcely been investigated. The aim of this study was to examine the response of OPO reactivity to the Kraepelin test as a mental arithmetic stressor in smokers and nonsmokers in addition to measuring uric acid and IgA concentrations, flow rate, amylase activity as a salivary stress marker, thiocyanate $\left(\mathrm{SCN}^{-}\right)$level and ultra-weak chemiluminescence (UCL) level, which is indicative of salivary antioxidative and antibacterial abilities. Furthermore, we studied the effect of smoking on the response of SPO and MPO activity to mental stress.

\section{MATERIALS AND METHODS}

\section{Experimental design and saliva collection}

The subjects were 39 non-smokers (20 male and 19 female) and 10 smokers (9 male and 1 female), all students at the School of Pharmaceutical Science, University of Shizuoka. Their mean age \pm standard deviation (SD) was $21.3 \pm 1.1$ (range 20-25) and $21.8 \pm 0.7$ (range 21-23) years, respectively. The aim of the experiment was explained to the subjects and consent was obtained after confirmation that they fully understood the experiment. The Kraepelin psychodiagnostic test (KN type, Employment Research, Tokyo, Japan) (Kuraishi et al., 1957) was used as a psychological stressor and was conducted between 14:00 and 16:00, $1 \mathrm{hr}$ or more after lunch or their last smoke. Subjects were assigned a Salivette (SARSTEDT, Nümbrecht, Germany) to collect saliva according to instructions. During collection, the Salivette was freely positioned in the oral cavity and therefore whole saliva composed of parotid, submandibular and sublingual saliva, was collected. Subjects were placed in a sitting position in a quiet environment for 5 min to ease their psychological stress, and then saliva was sampled 30 min before, just before, immediately after, and $30 \mathrm{~min}$ after the beginning of the experiment. Subjects could move freely for $30 \mathrm{~min}$ before and after the test. The samples were stored at $-30^{\circ} \mathrm{C}$ until the measurements. This experimental design was approved by the Ethics Committee of the University of Shizuoka.

\section{Salivary flow rate and protein assay}

Saliva was defrosted on ice and centrifuged at $1000 \mathrm{~g}$ for $20 \mathrm{~min}$. Only the liquid component volume of saliva was measured and the salivary flow rate was expressed in $\mathrm{ml} / \mathrm{min}$. The secretory immunoglobulin A ( $\operatorname{sg} \mathrm{A}$ ) level was measured by ELISA using peroxidase-conjugated goat antibody to human IgA as previously described (Takagi et al., 2005). Amylase activity was determined using the quantitative kinetic determination kit (Wako, Osaka, Japan) (Flick et al., 1970).

\section{Detection of UCL}

The detection of salivary UCL was measured as described before (Takagi et al., 2005). In brief, $200 \mu \mathrm{l}$ of saliva was placed on filter-paper (ADVANTEC, Tokyo, Japan) in a plastic dish (Nunc, Tokyo, Japan) 
Comparison of peroxidase response in saliva of smokers and non-smokers.

and $1 \mathrm{ml}$ of $3 \mathrm{mM}$ gallic acid was added. After mixing for $30 \mathrm{sec}$ at $100 \mathrm{rpm}$ at room temperature, the dish was set in the UCL measuring counter C767 (Hamamatsu Photonics, Hamamatsu, Japan). After the addition of 1 $\mathrm{ml}$ of $3 \%(\mathrm{w} / \mathrm{v})$ hydrogen peroxide $\left(\mathrm{H}_{2} \mathrm{O}_{2}\right)$ to the saliva preparation, the reaction commenced. The UCL in the present study was defined as the total number of photons for $100 \mathrm{sec}$ after addition of $\mathrm{H}_{2} \mathrm{O}_{2}$.

\section{Determination of $\mathrm{SCN}^{-}$concentration}

$\mathrm{SCN}^{-}$concentration was measured spectrophotometrically as described by Aune and Thomas (Aune and Thomas, 1977). In brief, $50 \mu \mathrm{l}$ of the sample was added to a mixture of $400 \mu \mathrm{l}$ of $0.1 \mathrm{M} \mathrm{HCl}$ and $100 \mu \mathrm{l}$ of $0.1 \mathrm{M}$ ferric chloride. After centrifugation at $1000 \mathrm{~g}$ for $1 \mathrm{~min}$, the absorbance of the supernatant due to $\mathrm{FeSCN}^{2+}$ was measured at $450 \mathrm{~nm}$.

\section{Determination of uric acid concentration}

The uric acid concentration was measured with a kit (Wako). In this assay, uric acid was transformed by uricase into allantoin and $\mathrm{H}_{2} \mathrm{O}_{2}$, which, under the catalytic influence of peroxidase, oxidized the chromogen (4-aminophenazone/N-ethyl-methylaniline propanesulfonate sodium) to form a red compound, the intensity of whose color was proportional to the amount of uric acid present in the sample; and it was read at a wavelength of $540 \mathrm{~nm}$.

\section{Peroxidase activity}

Oral peroxidase (OPO) activity was measured according to the 2-nitro-benzoic acid-thiocyanate (NBS-SCN) assay (Pruitt et al., 1990). Briefly, in this assay, 5,5'-dithiobis, 2-nitrobenzoic acid (DTNB) is reduced to NBS by the addition of $\beta$-mercaptoethanol.
The disappearance of NBS while it reacted with $\mathrm{OSCN}^{-}$, the product of OPO, was monitored at $412 \mathrm{~nm}$ at $\mathrm{pH}$ 5.6. One unit of activity was defined as the level needed to cleave $1 \mu \mathrm{M}$ of $\mathrm{NBS} / \mathrm{min}$ at $22^{\circ} \mathrm{C}$ using a molar extinction coefficient of 12,800.

Salivary peroxidase (SPO) and myeloperoxidase (MPO) were also determined using a kinetic spectrophotometric method. The NBS-Cl activity was used to calculate the contribution of MPO to the total (SPO + MPO) NBS-SCN activity.

\section{Statistical analysis}

GraphPad Prism was used for statistical calculations. A one-way analysis of variance (ANOVA) for repeated measures was utilized for evaluating the flow rate and UCL level; concentrations of $\operatorname{sg} \mathrm{A}$ and uric acid and activities of amylase and peroxidase, following a Dunnet multiple comparison test as described in the instruction manual of GraphPad Prism. An unpaired T-test was used to evaluate differences between groups. The level of statistical significance was set at $\mathrm{p}<0.05$.

\section{RESULTS}

\section{Effect of the Kraepelin test on biochemical parame- ters in whole saliva}

To examine the effect of the Kraepelin test on biochemical parameters in whole saliva, we measured several parameters. A significant increase of flow rate in the non-smoking group was detected at $30 \mathrm{~min}$ after the test, but there was no significant change in the smoking group (Table 1). The IgA concentration and salivary UCL level also increased significantly just after the test in the non-smoking group but these

Table 1. Effect of the Kraepelin test on biochemical parameters in whole saliva of smokers and non-smokers.

\begin{tabular}{|c|c|c|c|c|c|}
\hline & & \multicolumn{2}{|c|}{ Time before Test (min) } & \multicolumn{2}{|c|}{ Time after Test (min) } \\
\hline & & 30 & 0 & 0 & 30 \\
\hline Flow rate & non-smokers II & $1.44 \pm 0.51$ & $1.74 \pm 0.56$ & $1.73 \pm 0.60$ & $1.94 \pm 0.69 * *$ \\
\hline$(\mathrm{ml} / \mathrm{min})$ & smokers & $1.68 \pm 0.71$ & $1.84 \pm 0.65$ & $1.81 \pm 0.74$ & $1.81 \pm 0.72$ \\
\hline $\operatorname{Ig} \mathrm{A}$ & non-smokers $\mathbb{I}$ & $9.85 \pm 5.20$ & $9.72 \pm 5.78$ & $12.71 \pm 5.78^{*}$ & $8.37 \pm 4.17$ \\
\hline$(\mu \mathrm{g} / \mathrm{ml})$ & smokers & $6.80 \pm 2.82$ & $5.50 \pm 1.58^{\#}$ & $7.38 \pm 2.08^{\# \#}$ & $6.14 \pm 1.60$ \\
\hline$\alpha$-Amylase & non-smokers & $17.41 \pm 13.50$ & $15.66 \pm 8.49$ & $18.45 \pm 11.55$ & $16.41 \pm 9.24$ \\
\hline$\left(\times 10^{4} \mathrm{U} / \mathrm{ml}\right)$ & smokers & $14.72 \pm 9.38$ & $15.58 \pm 10.08$ & $16.86 \pm 9.24$ & $16.41 \pm 9.56$ \\
\hline $\mathrm{UCL}\left(\times 10^{4}\right)$ & non-smokers $\mathbb{I}$ & $13.02 \pm 5.92$ & $13.02 \pm 6.53$ & $16.62 \pm 7.72 *$ & $11.44 \pm 4.28$ \\
\hline (counts/100 sec) & smokers & $9.73 \pm 3.46$ & $9.40 \pm 2.10$ & $11.40 \pm 3.98^{\#}$ & $10.33 \pm 2.85$ \\
\hline
\end{tabular}

Date are expressed as the mean \pm SD ( 39 non-smokers and 10 smokers). Ione-way analysis of variance $\mathrm{p}<0.05$. $*$ Dunnet and $* *$ Dunnet test vs. 30 min before the test $\mathrm{p}<0.05$ and $\mathrm{p}<0.01$. "Unpaired and ${ }^{\#}$ Unpaired T-test test vs. non-smokers $\mathrm{p}<0.05$ and $\mathrm{p}<0.01$. 
parameters in the non-smoking group did not change significantly. In addition, the $\operatorname{IgA}$ concentration and UCL level just after the test were significantly higher in the non-smokers than smokers. Amylase activity slightly increased but was not significantly affected by the test in either group.

\section{Influence of smoking on thiocyanate concentration and antioxidant factors}

The mean level of $\mathrm{SCN}^{-}$was significantly higher in the smoking group $(0.99 \pm 0.71 \mathrm{mM})$ than nonsmoking group $(0.49 \pm 0.36 \mathrm{mM})$ at $30 \mathrm{~min}$ before the Kraepelin test and increased significantly just after $(0.77 \pm 0.38 \mathrm{mM})$ and decreased $30 \mathrm{~min}$ after $(0.57 \pm$ $0.29 \mathrm{mM}$ ) the test in the non-smoking group (Table 2). No significant change in the $\mathrm{SCN}^{-}$level was observed in the smoking group.

The uric acid concentration was slightly higher in the non-smoking group than smoking group but not significantly so, and was not affected by the test in either group. The OPO activity was greater in the nonsmoking group within each session and a significant increase was observed just after the test in the nonsmoking group.

\section{Response of SPO and MPO activity to Kraepelin test}

OPO activity is mainly composed of SPO and MPO activity. We next studied whether the response of SPO and MPO activity to mental stress was different between non-smokers and smokers. SPO activity was not changed by the Kraepelin test in either group. On the other hand, in non-smokers, MPO activity increased significantly just after the test $(227.8 \pm 229.4$ $\mathrm{mU} / \mathrm{ml})$, compared with that $30 \mathrm{~min}$ before $(102.3 \pm$ $118.3 \mathrm{mU} / \mathrm{ml}$ ) (Fig.1). A meaningful change in MPO activity was not detected in the smoking group.

\section{DISCUSSION}

Saliva is the first body fluid to encounter exogenous materials or gases such as cigarette smoke (CS) that penetrate the human body. Free radicals, reactive oxygen species (ROS), and reactive nitrogen species in inhaled CS have been suggested to mount a constant and direct attack on the oral epithelial cells, gradually accumulating and causing a step-wise malignant transformation. Therefore, precise information on the antioxidative defense system in saliva is needed. The purpose of this study was to examine whether smoking effects OPO reactivity to mental stress.

The results of the present study showed that defensive components are stronger in non-smokers than smokers. The IgA concentration, Amylase activity, and UCL level were higher in the non-smoking group than smoking group regardless of the Kraepelin test. In our system, OPO catalyzes the oxidation of salivary $\mathrm{SCN}^{-}$by $\mathrm{H}_{2} \mathrm{O}_{2}$ to the antimicrobial component hypothiocyanate $\left(\mathrm{OSCN}^{-}\right)$with the emission of $\mathrm{UCL}$ as follows (Goi et al., 2007).

$$
\stackrel{\mathrm{OPO}}{\mathrm{H}_{2} \mathrm{O}_{2}+\mathrm{SCN}^{-} \rightarrow \mathrm{OSCN}^{-}+\mathrm{H}_{2} \mathrm{O}+\mathrm{UCL} \uparrow}
$$

Therefore, the amount of UCL reflects the ability to consume $\mathrm{H}_{2} \mathrm{O}_{2}$ as an antioxidant and produces $\mathrm{OSCN}^{-}$. The function of $\mathrm{OSCN}^{-}$in the oral cavity has been discussed in relation to antimicrobial activity (Spiegeleer et al., 2005; Sermon et al., 2005) and the UCL level also reflects the strength of the innate immune system such as the antibacterial system. The IgA concentration and UCL level in the non-smokers increased significantly just after the Kraepelin test. Flow rate also increased $30 \mathrm{~min}$ after the test in the non-smokers. Some studies reported that cigarette con-

\begin{tabular}{|c|c|c|c|c|c|c|c|c|c|}
\hline \multirow{3}{*}{$\mathrm{SCN}^{-}(\mathrm{mM})$} & \multirow{4}{*}{$\begin{array}{l}\text { non-smokers II } \\
\text { smokers }\end{array}$} & \multicolumn{4}{|c|}{ Time before Test (min) } & \multicolumn{4}{|c|}{ Time after Test (min) } \\
\hline & & \multicolumn{2}{|c|}{30} & \multicolumn{2}{|c|}{0} & \multicolumn{2}{|l|}{0} & \multicolumn{2}{|l|}{30} \\
\hline & & $0.49 \pm$ & 0.36 & $0.61 \pm$ & 0.32 & $0.77 \pm$ & $0.38 * *$ & $0.57 \pm$ & 0.29 \\
\hline & & $0.99 \pm$ & $0.71^{\# \#}$ & $0.82 \pm$ & 0.64 & $0.85 \pm$ & 0.54 & $0.63 \pm$ & 0.49 \\
\hline \multirow[t]{2}{*}{ Uric acid (mg/dl) } & non-smokers & $2.27 \pm$ & 0.75 & $2.39 \pm$ & 0.95 & $2.54 \pm$ & 1.17 & $2.34 \pm$ & 0.99 \\
\hline & smokers & $2.21 \pm$ & 0.86 & $2.14 \pm$ & 1.05 & $2.31 \pm$ & 1.18 & $2.12 \pm$ & 0.87 \\
\hline \multirow[t]{2}{*}{ OPO (mU/ml) } & non-smokers II & \multicolumn{2}{|c|}{$711.3 \pm 422.2$} & \multicolumn{2}{|c|}{$776.8 \pm 420.9$} & \multicolumn{2}{|c|}{$932.1 \pm 529.0^{*}$} & \multicolumn{2}{|c|}{$733.2 \pm 408.9$} \\
\hline & smokers & $516.2 \pm$ & 2.3 & $582.1 \pm$ & 87.8 & $661.7 \pm$ & 32.8 & $602.4 \pm$ & 03.2 \\
\hline
\end{tabular}

Table 2. Mean levels of $\mathrm{SCN}^{-}$and peroxidase activity in saliva from smokers and non-smokers.

Data are expressed as the mean \pm SD (39 non-smokers and 9 smokers). II one-way analysis of variance p $<0.05$. $*$ Dunnet and

**Dunnet test vs. 30 min before the test $\mathrm{p}<0.05$ and $\mathrm{p}<0.01$. ${ }^{\#}$ Unpaired T-test test vs. non-smokers $\mathrm{p}<0.01$. 
Comparison of peroxidase response in saliva of smokers and non-smokers.

sumption had a negative correlation with salivary flow and an altered flow rate would also affect the washout, dilution, and clearance of OPO released from bleaching systems (Hannig et al., 2006). These results indicate that smoking suppresses the quick response of the innate immune system to psychological stress such as the mental arithmetic test.

In an epidemiological study, measurement of the $\mathrm{SCN}^{-}$level might be a valuable tool for studying the actual effect of smoking on the human body (Densen $e t$ $a l ., 1967)$. CS contains hydrogen cyanide, which is metabolized by the liver to $\mathrm{SCN}^{-}$. $\mathrm{SCN}^{-}$is specifically sequestered from the plasma by the parotid gland and is secreted by this gland into the oral cavity (Reznick et al., 2003). The levels of $\mathrm{SCN}^{-}$were higher in smokers than in non-smokers, a result supported by other studies (Zappacosta et al., 1999; Kanehira et al., 2006). However, $\mathrm{SCN}^{-}$levels increased significantly just after the Kraepelin test only in the non-smoking group. The uric acid concentration did not differ between the groups significantly and OPO activity was higher in the non-smoking group in all sessions. These results were consistent with reports that CS attacked antioxidative enzymes, reducing their activity severely, rather than molecules such as uric acid (Zappacosta et al., 1999; Nagler et al., 2001). The marked 65-70\% loss of OPO activity caused by cyanate in CS was prevented by pre-incubation of the saliva with hydroxocobal-

SPO

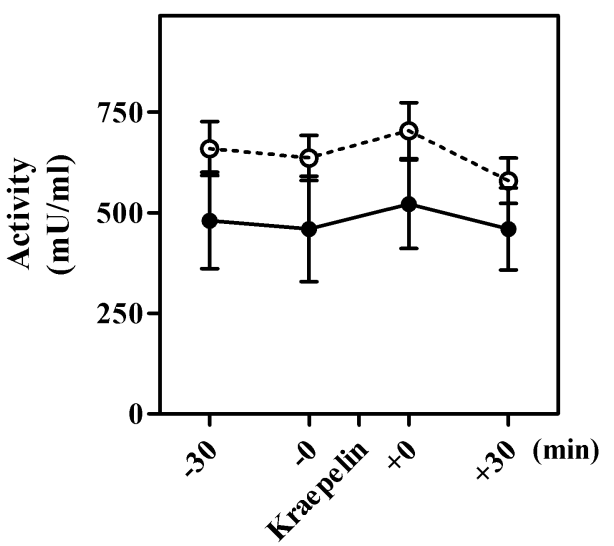

amine, a known chelator of cyanate (Klein et al., 2003). This indicated that cyanide was most probably the agent responsible for the CS-associated loss of salivary OPO activity. Moreover, a significant increase was observed only in the non-smoking group. OPO, $\mathrm{SCN}^{-}$, and $\mathrm{H}_{2} \mathrm{O}_{2}$ constitute an antimicrobial system (Tenovuo et al., 1985; Prudy et al., 1983; Thomas et al., 1994) and a hypothesis that salivary $\mathrm{SCN}^{-}$can protect the stomach from $\mathrm{OH}$ radicals formed by ascorbic acid/ $\mathrm{H}_{2} \mathrm{O}_{2} / \mathrm{Fe}$ (II) systems under acidic conditions was proposed (Takahama and Oniki, 2004). Therefore, the change in OPO activity and $\mathrm{SCN}^{-}$concentration may have a significant effect not only on the oral cavity, but also on other sites in the body, and CS could suppress the quick response of the innate immune system.

We calculated the response of SPO and MPO activity to mental arithmetic stress. SPO activity was always higher in the non-smoking than smoking group. Furthermore, MPO activity increased significantly just after the Kraepelin test only among the non-smokers. Both SPO and MPO can catalyze the oxidation of $\mathrm{SCN}^{-}$(Thomas and Fishman, 1986), but MPO is also able to oxidize $\mathrm{Cl}^{-}$and $\mathrm{OCl}^{-}$is a more potent oxidizing agent than $\mathrm{OSCN}^{-}$(Mansson-Rahemtulla et al., 1986). Usually, an increased output of MPO is thought to reflect a certain grade of infection of parotid glands, resulting in leukocyte infiltration and the production of MPO or inflammatory markers. However, our results
MPO

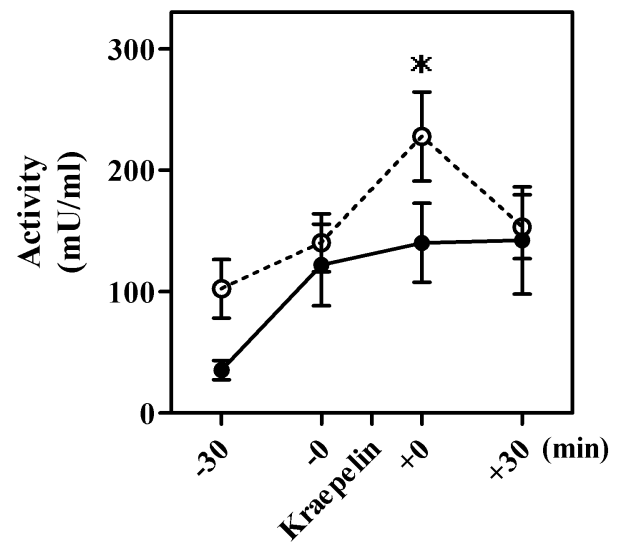

Fig. 1. Effect of the Kraepelin test on peroxidase activity of SPO and MPO. Data are expressed as the mean \pm $\operatorname{SEM}$ ( 0:39 non-smokers and :6 smokers). The overall test of differences among the times was statistically significant ( $\mathrm{p}<0.05$ by one-way analysis of variance). $*$ Dunnet test vs. 30 min before the test $\mathrm{p}<0.05$. 
indicated that MPO activity increased very quickly due to mental stress and that the contribution of OPO activity changed from $30 \mathrm{~min}$ before $(10.8 \pm 8.6 \%)$ to just after the stress $(23.9 \pm 14.2 \%)$ only in the non-smoking group. From these results, MPO may be crucial to respond to acute stress besides inflammation and CS may suppress this response significantly. The mechanism by which CS inhibits the response of MPO to acute stress is not clear, but this finding may contribute to a more profound understanding of the effect of smoking on the mind and body.

\section{ACKNOWLEDGMENT}

This investigation was supported by Cooperation of Innovative Technology and Advanced Research in Evolutional Area (CITY AREA), Ministry of Education, Culture, Sports, Science and Technology in Japan.

\section{REFERENCES}

Amerongen, A.N., Bolscher, J.G.M. and Veerman, E.C.I. (2004): Salivary proteins: Protective and diagnostic value in cariology? Caries. Res., 38, 247-253.

Aune, T.M. and Thomas, E.L. (1977): Accumulation of hypothiocyanite ion during peroxidase-catalyzed oxidation of thiocyanate ion. Eur. J. Biochem., 80, 209-214.

Densen, P.M., Davidow, B., Bass, H.E. and Jones, E.W. (1967): A chemical test for smoking exposure. Arch. Environ. Health., 14, 865-874.

Flick, A.L., Bark, C.J. and Harrell, J.H. (1970): Serum amylase values by the Caraway method in hospitalized patients and normal controls. Amylase, 53, 458-461.

Goi, N., Takagi, K., Hirai, Y., Harada, H., Ikari, A., Terashima, Y., Kinae, N., Hiramatsu, M., Nakamura, K. and Ono, T. (2007): Effect of psychologic stress on peroxidase and thiocyanate levels in human saliva detected by ultraweak chemiluminescence. J. Health. Sci. (in press).

Hannig, C., Willenbucher, S., Becker, K., Mahony, C. and Attin, T. (2006): Recovery of peroxides in saliva during home bleaching - influence of smoking. J. Oral. Rehabil., 33, 533-541.

Kanehira, T., Shibata, K., Kashiwazaki, H., Inoue, N. and Morita, M. (2006): Comparison of antioxidant enzymes in saliva of elderly smokers and non-smokers. Gerodontology, 23, 38-42.
Klein, I., Nagler, R.M., Toffler, R., Vliet, A.V.D. and Reznick, A.Z. (2003): Effect of cigarette smoke on oral peroxidase activity in human saliva: Role of hydrogen cyanide. Free. Radic. Biol. Med., 35, 1448-1452.

Kranendonk, M., Commandeur, J.N.M., Laires, A., Rueff, J. and Vermeulen, N.P.E. (1997): Characterization of enzyme activities and cofactors involved in bioactivation and bioinactivation of chemical carcinogens in the tester strains Escherichia coli K12 MX100 and Salmonella typhimurium LT2 TA100. Mutagenesis, 12, 245254.

Kuraishi, S., Kato, M. and Tsujioka, B. (1957): Development of the "Uchida-Kraepelin psychodiagnostic test" in Japan. Psychologia, 1, 104-109.

Mansson-Rahemtulla, B., Baldone, D.C., Pruitt, K.M. and Rahemtulla, F. (1986): Specific assays for peroxidases in human saliva. Arch. Oral. Biol., 31, 661-668.

Nagao, A. and Terao, J. (1990): Antioxidant activity of 6-phosphatidyl-L-ascorbic acid. Biochem. Biophys. Res. Commun., 172, 385-389.

Nagler, R.M. (2003): Oral cancer induced by cigarette smoke - the mediatory role of the salivary antioxidant system. Anticancer. Res., 23, 5125 5128.

Nagler, R.M., Klein, I., Zarzhevsky, N., Drigues, N. and Reznick, A.Z. (2002): Characterization of the differentiated antioxidant profile of human saliva. Free. Radic. Biol. Med., 32, 268-277.

Nagler, R.M., Lischinsky, S., Diamond, E., Klein, I. and Reznick, A.Z. (2001): New insights into salivary lactate dehydrogenase of humansubjects. J. Lab. Clin. Med., 137, 363-369.

Nogueira, R.D., Alves, A.C., Napimoga, M.H., Smith, D.J. and Mattos-Graner, R.O. (2005): Characterization of salivary immunoglobulin A responses in children heavily exposed to the oral bacterium Streptococcus mutans: Influence of specific antigen recognition in infection. Infect. Immun., 73, 5675-5684.

Pruitt, K.M., Kamau, D.N., Miller, K., ManssonRahemtulla, B. and Rahemtulla, F. (1990): Quantitative, standardized assays for determining the concentrations of bovine lactoperoxidase, human salivary peroxidase, and human myeloperoxidase. Anal. Biochem., 191, 278286.

Pryor, W.A. (1997): Cigarette smoke radicals and the role of free radicals in chemical carcinogenicity. 
Comparison of peroxidase response in saliva of smokers and non-smokers.

Environ. Health. Perspect., 105, 875-882.

Purdy, M.A., Tenovuo, J., Pruitt, K.M. and White, W.E. (1983): Effect of growth phase and cell envelope structure on susceptibility of Salmonella typhimurium to the lactoperoxidase-thiocyanate-hydrogen peroxide system. Infect. Immun., 39, 1187-1195.

Reznick, A.Z., Klein, I., Eiserich, J.P., Cross, C.E. and Nagler, R.M. (2003): Inhibition of oral oral peroxidase activity by cigarette smoke: In vivo and in vitro studies. Free. Radic. Biol. Med., 34, 377-384.

Sermon, J., Vanoirbeek, K., Spiegeleer, P.D., Houdt, R.V., Aertsen, A. and Michiels, C.W. (2005): Unique stress response to the lactoperoxidasethiocyanate enzyme system in Escherichia coli. Res. Microbiol., 156, 225-232.

Spiegeleer, P.D., Sermon, J., Kristof, V., Aertsen, A. and Michiels, C.W. (2005): Role of porins in sensitivity of Escherichia coli to antibacterial activity of the lactoperoxidase enzyme system. Appl. Environ. Microbiol., 71, 3512-3518.

Stone, K., Bermudez, E., Zang, L.Y., Carter, K.M., Queenan, K.E. and Pryor, W.A. (1995): The ESR properties, DNA nicking, and DNA association of aged solutions of catechol versus aqueous extracts of Tar from cigarette smoke. Arch. Biochem. Biophys., 319, 196-203.

Takagi, K., Hasunuma, T., Goi, N., Harada, H., Ikari, A., Hiramatsu, M., Nakamura, K. and Tsuboi, H. (2005): The effects of performance anxiety on salivary ultra-weak chemiluminescence. Stress and Health, 21, 263-268.
Takahama, U. and Oniki, T. (2004): Salivary thiocyanate/nitrite inhibits hydroxylation of 2-hydroxybenzoic acid induced by hydrogen peroxide/ Fe(II) systems under acidic conditions: Possibility of thiocyanate/nitrite-dependent scavenging of hydroxyl radical in the stomach. Biochim. Biophys. Acta, 1675, 130-138.

Tenovuo, J. (2002): Clinical applications of antimicrobial host proteins lactoperoxidase, lysozyme and lactoferrin in xerostomia: Efficacy and safety. Oral. Dis., 8, 23-29.

Tenovuo, J., Makinen, K.K. and Sievers, G. (1985): Antibacterial effect of lactoperoxidase and myeloperoxidase against Bacillus cereus. Antimicrob. Agents. Chemother., 27, 96-101.

Thomas, E.L. and Fishman, M. (1986): Oxidation of chloride and thiocyanate by isolated leukocytes. J. Biol. Chem., 261, 9694-9702.

Thomas, E.L., Milligan, T.W., Joyner, R.E. and Jefferson, M.M. (1994): Antibacterial activity of hydrogen peroxide and the lactoperoxidasehydrogen peroxide-thiocyanate system against oral streptococci. Infect. Immun., 62, 529-535.

Zappacosta, B., Persichilli, S., Mordente, A., Minucci, A., Lazzaro, D., Meucci, E. and Giardina, B. (2002): Inhibition of salivary enzymes by cigarette smoke and the protective role of glutathione. Hum. Exp. Toxicol., 21, 7-11.

Zappacosta, B., Persichilli, S., Sole, P.D., Mordente, A. and Giardina, B. (1999): Effect of smoking one cigarette on antioxidant metabolites in the saliva of healthy smokers. Arch. Oral. Biol., 44, 485-488. 